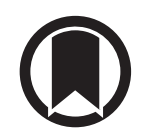

CrossMark

\section{Potential role of memantine in the prevention and treatment of COVID-19: its antagonism of nicotinic acetylcholine receptors and beyond}

\author{
To the Editor:
}

Recently, LEUNG et al. [1] proposed that $\alpha 7$-subtype nicotinic acetylcholine receptor ( $\alpha 7-\mathrm{nAChR})$ antagonists might decrease angiotensin-converting enzyme (ACE)2 receptor expression in respiratory epithelium and, hence, prevent severe acute respiratory syndrome coronavirus 2 (SARS-CoV-2) invasion of pulmonary epithelial cells. Let us further theoretically evaluate this assertion and contribute to the quest for potential medications that might reduce virulence and pathogenicity of coronavirus disease 2019 (COVID-19). Smoking may be associated with progression and negative outcome of COVID-19 [1]. The receptor-binding domain of the S protein (spike) on the surface of SARS-CoV-2 interacts with the ACE2 receptor, which is an entry point of the virus into host respiratory cells [2]. On the respiratory epithelium cells of smokers and patients with COPD there is higher expression of this "viral receptor" (ACE2 receptor) [1]. Nicotine binds and stimulates $n A C h R$, specifically the $\alpha 7$ subtype, which are localised in lungs and various other tissues, especially in the central nervous system. Increased expression of ACE2 receptors is mediated by stimulation of $\alpha 7-\mathrm{nAChR}$. Nicotine, by its agonism on $\alpha 7-\mathrm{nAChR}$, might promote entry of SARS-CoV-2 into the respiratory epithelium through ACE2 receptors [1]. Additionally, some evidence suggests that SARS-CoV-2, along with other human coronaviruses, is neurotropic and neurovirulent [3]. Altogether, it is of utmost importance to search for medications that might exert protective effects both at the periphery, at the entry point of SARS-CoV-2 infection, but also in the central nervous system where the virus might propagate.

Memantine reduces excitotoxity in the central nervous system by its noncompetitive antagonism of the $N$-methyl-D-aspartate (NMDA) glutamate receptors [4]. Memantine has greater affinity for extrasynaptic than synaptic NMDA receptors, enabling glutamate to exert its physiological role in the processes of learning, memory formation and neuronal plasticity by stimulating synaptic NMDA receptors [4]. However, in conditions of excessive extracellular accumulation of glutamate, initiated by various inflammatory and oxidative processes, memantine significantly blocks extrasynaptic NMDA receptors, protecting cells from the glutamate excitotoxity [4]. The effectiveness of memantine in the treatment of different neuropsychiatric disorders, from various forms of dementia, autism, schizophrenia and depression to neuropathic pain and Parkinson's disease, has been tested in more than 100 trials [4]. It is approved as a safe and effective medication by both the US Food and Drug Administration and the European Medicines Agency for the treatment of "moderate to severe Alzheimer's disease" [4]. Memantine, in addition to its noncompetitive NMDA receptor antagonism, is very potent $\alpha 7-n A C h R$ antagonist [5]. By its $\alpha 7-\mathrm{nAChR}$ antagonism, it blocks meningitic Escherichia coli K1 bacteria neuroinvasion in mice [5]. It may also exert its protective, anti-inflammatory effects by suppression of cytokine expression, as demonstrated in an experimental model of lung injury [6]. As an adamantane derivate, in cell cultures memantine inhibits human coronavirus strain OC43 (HCoV-OC43) replication after virus attachment to the cell receptor, acting as an antiviral drug [7]. Infection with HCoV-OC43, in particular mutated surface protein $\mathrm{S}$, increases levels of inflammation by release of pro-inflammatory cytokines such as tumour necrosis factor- $\alpha$, interleukin-1 and interleukin- 6 , and by inducing

@ERSpublications

Memantine, as an antagonist of $\alpha 7-n A C h R$ and NMDA receptors, may decrease ACE2 receptor expression and reduce oxidative stress and inflammation. Hence, memantine may potentially reduce SARS-CoV-2 virulence. https://bit.ly/2AZHiVg

Cite this article as: Hasanagic S, Serdarevic F. Potential role of memantine in the prevention and treatment of COVID-19: its antagonism of nicotinic acetylcholine receptors and beyond. Eur Respir J 2020; 56: 2001610 [https://doi.org/10.1183/13993003.01610-2020]. 
microphage/microglial hyperactivation in the central nervous system [7, 8]. Memantine may counteract these deleterious effects by inhibiting activity of microglia $[8,9]$. Moreover, neuroinvasion with mutated surface protein $\mathrm{S}$ variants of $\mathrm{HCoV}-\mathrm{OC} 43$ resulted in paralysis of experimental animals due to glutamate excitotoxicity. Memantine ameliorated these motor disturbances, reduced mortality rates and inhibited coronavirus replication rate in the central nervous system, dose-dependently [7, 9]. Additionally, memantine might exert anti-inflammatory effects by reducing angiogenesis and brain lymphocyte infiltration, as shown in mice infected with Japanese encephalitis virus [10]. In conclusion, we hypothesise that memantine may reduce virulence and pathogenicity of SARS-CoV-2 and potentially exert its effects both in lungs and brain. However, such claims require further thorough experimental, epidemiological and clinical confirmation.

Senad Hasanagic ${ }^{1}$ and Fadila Serdarevic ${ }^{2}$

${ }^{1}$ Clinical Center University of Sarajevo, Dept of Psychiatry, Sarajevo, Bosnia and Herzegovina. ${ }^{2}$ Erasmus MC, Dept of Epidemiology, Rotterdam, The Netherlands.

Correspondence: Senad Hasanagic, Clinical Center University of Sarajevo, Dept of Psychiatry, Sarajevo, Bosnia and Herzegovina. E-mail: hasanagic.sen@gmail.com

Received: 6 May 2020 | Accepted after revision: 5 June 2020

Conflict of interest: S. Hasanagic has nothing to disclose. F. Serdarevic has nothing to disclose.

\section{References}

$1 \quad$ Leung JM, Yang CX, Sin DD. COVID-19 and nicotine as a mediator of ACE-2. Eur Respir J 2020; 55: 2001261

2 Tay MZ, Poh CM, Rénia L, et al. The trinity of COVID-19: immunity, inflammation and intervention. Nat Rev Immunol 2020; 20: 363-374.

3 Li YC, Bai WZ, Hashikawa T. Response to commentary on "The neuroinvasive potential of SARS-CoV-2 may play a role in the respiratory failure of COVID-19 patients". J Med Virol 2020; 92: 707-709.

4 McShane R, Westby MJ, Roberts E, et al. Memantine for dementia. Cochrane Database Syst Rev 2019; 3: CD003154.

5 Yu JY, Zhang B, Peng L, et al. Repositioning of memantine as a potential novel therapeutic agent against meningitic E. coli-induced pathogenicities through disease-associated alpha7 cholinergic pathway and RNA sequencing-based transcriptome analysis of host inflammatory responses. PLoS One 2015; 10: e0121911.

6 Cheng Q, Fang L, Feng D, et al. Memantine ameliorates pulmonary inflammation in a mice model of COPD induced by cigarette smoke combined with LPS. Biomed Pharmacother 2019; 109: 2005-2013.

7 Brison E, Jacomy H, Desforges $\mathrm{M}$, et al. Novel treatment with neuroprotective and antiviral properties against a neuroinvasive human respiratory virus. J Virol 2014; 88: 1548-1563.

8 Jacomy H, St-Jean JR, Brison E, et al. Mutations in the spike glycoprotein of human coronavirus OC43 modulate disease in BALB/c mice from encephalitis to flaccid paralysis and demyelination. J Neurovirol 2010; 16: 279-293.

9 Wu HM, Tzeng NS, Qian L, et al. Novel neuroprotective mechanisms of memantine: increase in neurotrophic factor release from astroglia and anti-inflammation by preventing microglial activation. Neuropsychopharmacology 2009; 34: 2344-2357.

10 Sun L, Zhou M, Liu C, et al. Memantine can relieve the neuronal impairment caused by neurotropic virus infection. J Med Virol 2019; 91: 935-940. 